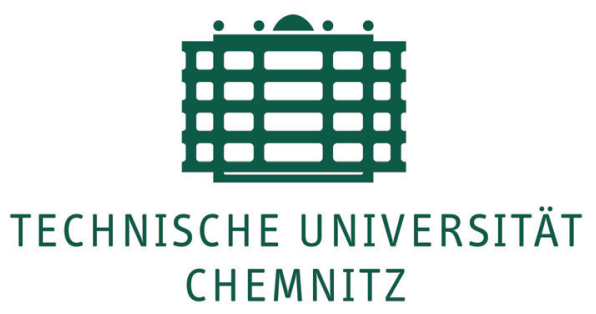

First published in:

Electrochemical Society Transactions. - 2 (23) 45 - 62 (2007)

\title{
Theoretical Treatment of 3-phenylsubstituted Thiophenes and their Intrinsically Conducting Polymers
}

\author{
Wasim Alhalasah and Rudolf Holze
}

MONARCH - Dokument

http://archiv.tu-chemnitz.de/

Copyright (c) The Electrochemical Society, reproduced with permission.

www.electrochem.org 


\title{
Theoretical Treatment of 3-phenylsubstituted Thiophenes and their Intrinsically Conducting Polymers
}

\author{
Wasim Alhalasah and Rudolf Holze
}

Technische Universität Chemnitz, Institut für Chemie, D-09107 Chemnitz, Germany

\begin{abstract}
A series of 3-( $p$-X-phenyl) thiophene monomers $\left(\mathrm{X}=-\mathrm{H},-\mathrm{CH}_{3},-\right.$ $\mathrm{OCH}_{3},-\mathrm{COOC}_{2} \mathrm{H}_{5},-\mathrm{COCH}_{3},-\mathrm{NO}_{2}$ ) was electrochemically polymerized to furnish polymer films that could be reversibly reduced and oxidized ( $n$ - and $p$-doped). The oxidation potentials of the monomers and formal potentials of the $n$ - and $p$-doping processes of polymers were correlated with resonance and inductive effects of the substituents on the phenyl ring as well as the semiempirically calculated heats of formation of the monomer radical cations. Moreover, the oxidation potentials of the monomers were correlated with the ionization potentials of the monomers calculated using density functional theory. The reactivity for coupling reactions and the major regioselective products of the polymerization reaction of mono- and oligo-3-phenylthiophenes are inferred from the calculated lone electron spin densities of the respective radical cations. The ionization potentials, which correspond to the energies for generating radical cations during oxidative processes were estimated.
\end{abstract}

\section{Introduction}

Numerous conjugated polymers have been synthesized since the discovery in 1977 that polymers can conduct electricity when doped (1). Particular interest has been attracted by substituted regioregular polythiophenes (2), which stand out as some of the most promising members of the conjugated polymer family, because they are stable and processable, they show very high charge carrier mobilities (3) and they become highly conducting upon doping (4). Thus polythiophenes constitute a class of conjugated polymers that has been incorporated in electroluminescent devices such as polymer light emitting diodes (LEDs) (5), microcavities (6), solar cells (7), and recently, optically pumped lasers (8).

Despite the fact that the possibility of $n$-doping is very important for applications in the fields of electrochromism, energy storage $(9,10)$ and bipolar electronic devices $(11)$, it is only infrequently reported for polythiophenes in the literature. Low electron affinity of the polymer may force the reduction potential out of the electrochemical potential windows accessible with commonly employed organic solvents. In addition, the occasionally extreme sensitivity of the $n$-doped state to oxygen and water makes this process more difficult to study.

Sato et al. (12) have found that poly-3-phenylthiophene is highly $p$-dopable and also suggested its application in a $p-n$ junction diode. The high $p$-doping activity of poly-3phenylthiophene was explained in terms of a favorable conjugation effect between the phenyl rings and the polythiophene backbone (13). On the other hand, Onoda et al. (14) studied the $n$-doping properties of poly-3-phenylthiophene films and found a high degree of electrochemical reversibility. However, this group concluded that rather than being in 
conjugation with the polythiophene backbone, the phenyl rings were perpendicular to it and the interchain charge transport processes limited the observed electronic properties.

Sato et al. (13) and Guerrero et al. (15) further demonstrated that the oxidation potential of poly-3-phenylthiophene increased when an electron-withdrawing substituent was placed on the phenyl ring and the electron-donating groups produced a stable aniondoped material. Thus, the oxidation potential decreased.

The synthesis of $98 \%$ head to tail (HT) poly(3-alkylthiophene)s has resulted in substantial improvements in conjugation length and electronic properties $(16,17)$. Such synthesis can be performed as an asymmetric chemical activation of 2- and 5- positions on the thiophene ring, which results in HT coupling. On the other hand, Andersson et al. (18) have reported that regioselective poly(3-(4-octylphenyl)thiophene) (HT content ca. $94 \%$ ) can be prepared using ferric(III)chloride $\left(\mathrm{FeCl}_{3}\right)$ as an oxidant.

Ando et al. (19) have calculated the lone electron spin densities at C-2 and C-5 of radical cations for thiophene and eleven 3 -substituted thiophenes together with their ionization potentials. They have concluded that alkyl substituents such as methyl, $n$-hexyl and (S-2-methyl)butyl groups, cause small differences of the spin densities between C-2 and $\mathrm{C}-5$, which implies that both carbons have similar reactivities for coupling reactions while the other type of electron donating groups, such as methoxy, methylsulfanyl, phenyl, phenoxy, 4-methoxyphenyl and 4-alkylphenyl groups, cause significant asymmetric distributions in the spin densities, which provides a strong directing power of reactivity for these radical cations. The major regioselective products of the propagation reactions of 3-(methylsulfanyl)thiophene were well understood in terms of the magnitude of calculated spin densities of the oligomers. The steric hindrance would not interfere with the Head to Head $(\mathrm{HH})$ coupling between the reactive 2-positions in this case

We have investigated the role of various para substituents $\left(-\mathrm{H},-\mathrm{CH}_{3},-\mathrm{OCH}_{3}\right.$, $\mathrm{COOC}_{2} \mathrm{H}_{5},-\mathrm{COCH}_{3},-\mathrm{NO}_{2}$ ) on the oxidation of the monomer and on $p$ - and $n$-doping processes of 3-phenylthiophene. Redox properties of the monomers and polymers obtained by cyclic voltammetry were correlated with Hammett substituent constants and semiempirically calculated heats of formation of monomer radical cations as well as the ionization potentials, which correspond to the energies for generating radical cations. The lone electron spin densities of radical cations, which are known as a good measure of reactivity for the coupling reaction, and the ionization potentials are calculated for a series of 3-phenylthiophenes $\left(\mathrm{R}=-\mathrm{H},-\mathrm{CH}_{3},-\mathrm{OCH}_{3},-\mathrm{COOC}_{2} \mathrm{H}_{5},-\mathrm{COCH}_{3},-\mathrm{NO}_{2}\right)$. In addition, the local spin densities are calculated for oligomers (from dimers to pentamers) of 3phenylthiophene to further support experimental results. This study attempts to provide a theoretical basis for the evaluation and selection of 3-phenylthiophenes that yields polymers with high head to tail (HT) content.

\section{Experimental Section}

Anodic electropolymerization was used to prepare polymers by applying a constant electrode potential (oxidation potential) for 2-4 minutes. After each polymerization process the film was washed with acetonitrile to remove any traces of oligomers.

All electrochemical experiments were carried out at room temperature with nitrogenpurged solutions. A three-compartment cell containing a Pt disc (diameter $=1 \mathrm{~mm}$ ) electrode $(99.99 \%$, Schiefer, Hamburg) embedded in glass was used as working electrode. The platinum disk electrode was polished with diamond polishing paste down to $0.3 \mu \mathrm{m}$ and then to $0.05 \mu \mathrm{m}$ with aqueous alumina slurry. A platinum sheet counter electrode, and a non-aqueous $\mathrm{Ag} / \mathrm{AgCl}$ reference electrode filled with the supporting electrolyte so- 
lution were used. The reference electrode potential was verified frequently with respect to an aqueous saturated calomel electrode because the employed non-aqueous reference electrode system is prone to potential drift. A custom built potentiostat interfaced with a standard PC via an ADDA-converter card operating with custom developed software was used to record cyclic voltammograms (CVs).

DFT (20 - 23) of the three-parameter compound functional of Becke (B3LYP) was used to optimize the geometry as well as to calculate the ionization potentials of neutral compounds and total atomic spin densities of the radical cations. The 6-31G(d) $(24-35)$ basis set was used to optimize the structures as well as the total spin densities, while the 3-21G(d) (36 - 42) basis set was used to calculate the ionization potentials for neutral compounds. The geometric structures of neutral molecules were optimized under no constraints. Nearly planar structures were used as the initial states because most of the crystalline oligothiophenes show planar conformations (43 - 45). On the other hand, the geometrical structures of the radical cations were optimized independently from the neutral molecules prior to the calculations of spin densities. Radical cations were treated as open shell systems (UB3LYP). The AM1 method was used for semiempirical calculations of the heats of formations (46). All calculations were performed using the Gaussian-98W software (47).

\section{Result and Discussion}

Scheme 1 shows the proposed mechanism for the electropolymerization of 3phenylthiophenes in analogy to the already known coupling reactions of related aromatic compounds (48 - 50). The first electrochemical step is the oxidation of the monomer (1) to its radical cation (2). Since the electron transfer reaction is much faster than the diffusion of the monomer from the bulk solution, it follows that a high concentration of radicals and a corresponding low concentration of neutral monomers is continuously maintained near the electrode surface. The second step involves the coupling of two radicals (2) to produce a dihydrodimer (3) dication that leads to a dimer (4) after the loss of two protons and rearomatization. This rearomatization constitutes the driving force of the chemical step. Due to the applied potential the dimer (4), which is more easily oxidized than the monomer, is present in its radical form (5) and undergoes further coupling with a monomeric radical (6). Electropolymerization then proceeds through successive electrochemical and chemical steps according to a general $\mathrm{E}(\mathrm{EC})_{\mathrm{n}}$ scheme, until the oligomer becomes insoluble in the electrolytic medium and precipitates onto the electrode surface. The likelihood of the first step can be estimated based on the ionization potential of the molecule while the likelihood of second step should be closely related to the spin density of the unpaired electron and the steric effects between the two cations.

Steric effects should play an important role in the coupling reactions of 3-phenylthiophenes. Since the radical cations have coplanar structures, the distance between the hydrogen at C-2 and the closest hydrogen in phenyl group is only $2.1 \AA(19,51)$. The generation of Head-to-head $(\mathrm{HH})$ linkage would be hindered due to the significant steric effect between thiophene rings and phenyl rings. Accordingly, the first coupling would predominantly generate a HT linkage resulting in formation of a high content of the Head-totail (HT) dimer. This view agrees well with the experimental results with poly (3-(4dodecylphenyl)thiophene) and poly(3-(4-butylphenyl)thiophene) $(52,53)$. 

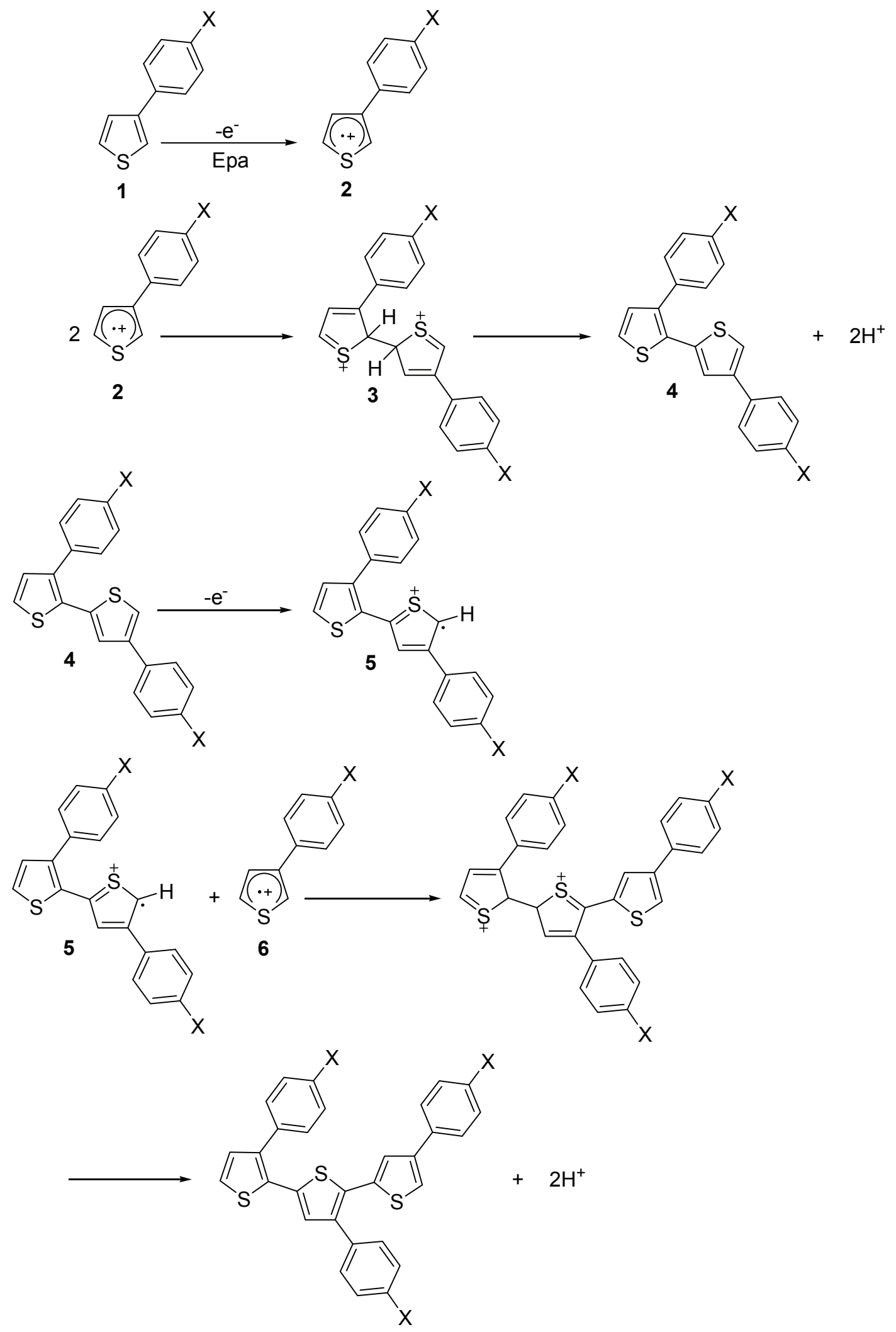

Scheme 1. Mechanism of the electropolymerization of 3-phenylthiophene derivatives.

The spin density at $\mathrm{C}-2$ of the radical cation of 3-phenylthiophene (1) is larger than that at $\mathrm{C}-5$ as shown in Fig. 1 . This implies that the former is more reactive than the latter. 
When two molecules of $\mathbf{1}$ are chemically coupled, three regioisomeric coupling products, Head to Head (HH) (2a), Head to Tail (HT) (2b) and Tail to Tail (TT) (2c), can be generated. Although each dimer has two preferential conformers, i.e. syn and anti, we consider only anti forms because the calculated total energies of the syn forms of $\mathbf{2 a}, \mathbf{2} \mathbf{b}$, and 2c are higher than those of the anti forms by $1.241,0.097$ and $0.551 \mathrm{kcal} / \mathrm{mol}$, respectively. In addition, syn conformers are rarely found in the crystallographic structures of thiophene oligomers. The proportions of the three types of coupling reactions that generate $\mathbf{2 a}-\mathbf{c}$ can be inferred from the magnitude of calculated total atomic spin densities and the steric effect of the substituents. For examining the initiating and propagating reactions, it is reasonable to assume that coupling reactions preferentially occur between the carbons having higher spin densities (54).

Fig. 1 summarizes the reaction paths of the succeeding coupling reactions of $\mathbf{1}$ based on the calculated spin densities. As already discussed, polymerization may proceed through the formation of HT linkages such as HT (2b) dimers and HT oligomers due to the high spin density at the 2-position $(\mathrm{C}-2)$ and the steric hindrance between phenyl groups of the monomer, but smaller amounts of the other coupling reactions, that is $\mathrm{HH}$ (2a) or TT (2c) linkage, may occur simultaneously.

The calculated spin densities at the termini of the oligomers thus generated are shown in brackets in Fig. 1. In case that the HT coupling of radical cation $\mathbf{1}$ occurs preferentially in the initiating reaction and the generation of $\mathbf{2 a}$ is negligibly small, the most reactive species is a radical cation $1 \rightarrow \mathbf{2 b} \rightarrow \mathbf{3 a} \rightarrow \mathbf{4 a} \rightarrow \mathbf{5 a} \rightarrow \mathbf{6 a}$ throughout the reactions. Considering the calculated spin density of each oligomer, the most probable path of propagation is as shown in Fig. 1. For instance, when a tetramer is formed from $\mathbf{3 a}$ and 1, two regio-isomers can be generated. However, since the spin density of $\mathbf{3 a}$ at the right terminus $(0.153)$ is significantly higher than that of the left terminus $(0.075)$, tetramer $\mathbf{4 a}$ should be preferentially formed. The same situation occurs for the reaction of $\mathbf{5 a}$ and $\mathbf{1}$. Repeating this process, the resultant polymer has HT linkage. In Fig. 1, thick lines indicate the dominant path of oligomerization, and pathways with low likelihood are indicated by dotted lines. Although the local spin densities at the reactive termini of oligomers gradually decrease as the number of thiophene rings increase, the second oxidation can reactivate the termini. In addition, it is known that the ionization potential gradually decreases as the number of thiophene rings increases (19). Therefore, this fact indicates that the generated oligomers are immediately oxidized, and thereby, the oligomers exit as reactive cations into the solution. As long as the concentrations of oligomers are significantly lower than that of $\mathbf{1}$, the oligomers should subsequently react with a radical cation of 1 . 


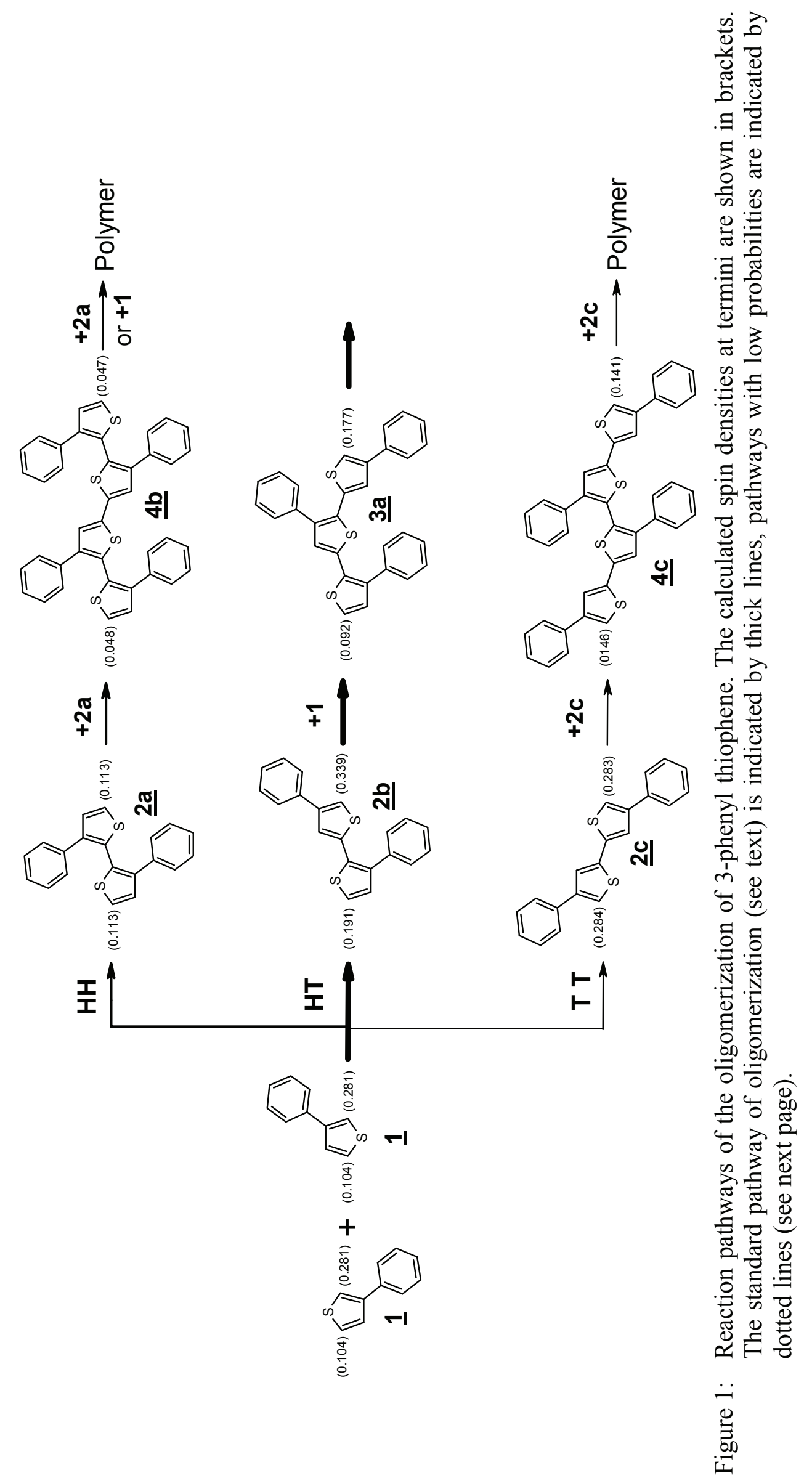




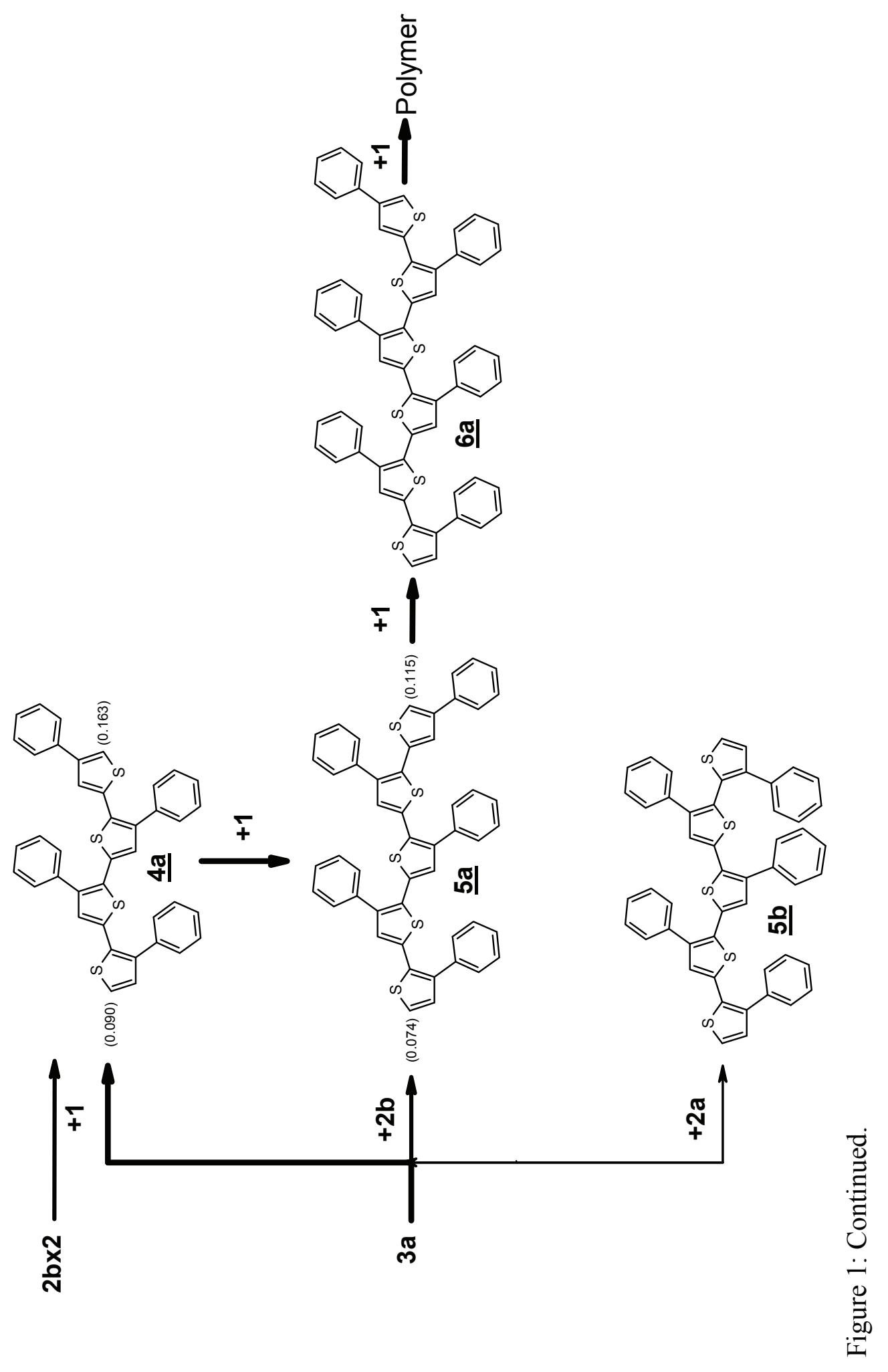




\begin{tabular}{|c|c|c|}
\hline 1 & $\mathbf{X}$ & Acronym \\
\hline $\bar{a}$ & $-\mathrm{H}$ & PTB \\
\hline $\mathrm{b}$ & $-\mathrm{CH}_{3}$ & PPT \\
\hline $\mathrm{c}$ & $-\mathrm{OCH}_{3}$ & PTAN \\
\hline $\mathrm{d}$ & $-\mathrm{COOC}_{2} \mathrm{H}_{5}$ & PETP \\
\hline $\mathrm{e}$ & $-\mathrm{COCH}_{3}$ & PTAP \\
\hline $\mathrm{f}$ & $-\mathrm{NO}_{2}$ & PTNB \\
\hline & & 2 \\
\hline
\end{tabular}

Table 1: Studied 3-X-phenylthiophene monomers 1and polymers 2

The possibility to undergo electropolymerization does not depend on the nature of the substituent on the phenyl ring. The monomers with electron withdrawing groups like $\mathrm{COCH}_{3}\left(\mathrm{Hammett}\right.$ constant $\left.\sigma_{p}=0.36\right)$ or $-\mathrm{NO}_{2}\left(\sigma_{p}=0.80\right)$ as well as with donor groups like $\mathrm{CH}_{3}\left(\sigma_{p}=-0.18\right)$ or $\mathrm{OCH}_{3}\left(\sigma_{p}=-0.15\right)$ were electrooxidized yielding stable electroactive polymers. The electropolymerization of the monomers with electron withdrawing (1d-f) substituents proceeds with low current efficiency and obviously requires higher anodic potentials, whereas those with electron donating groups (1a-c) show lower oxidation potential. The corresponding radicals are stabilized and formation of soluble short chain oligomers is more favorable (55). Alternatively these radicals can thus diffuse away from the electrode surface to form soluble oligomers in solution.

The oxidation potentials of the monomers (1a-f, Fig. 2) were measured by cyclic voltammetry at $\mathrm{d} E / \mathrm{d} t=100 \mathrm{mV} / \mathrm{s}$ in acetonitrile (first cycle) containing $0.2 \mathrm{M} \mathrm{Et}_{4} \mathrm{NBF}_{4}$ and a low monomer concentration $(0.05 \mathbf{M})$ in order to prevent polymerization. Soluble oligomers were observed to stray away from the electrode with subsequent coloration of the monomers solution, and the resulting polymer films were very thin, especially the ones with electron donating substituents.

Cyclic voltammograms of polymers recorded at a scan rate of $\mathrm{d} E / \mathrm{d} t=100 \mathrm{mV} / \mathrm{s}$ are shown in Fig. 3 for the studied polymer films. Formal potentials for both $p$-and $n$-doping processes were estimated by averaging the anodic and cathodic peak potentials of each process $\left(E^{o x}=\left(E_{p a}^{o x}+E_{p c}^{o x}\right) / 2\right.$ and $\left.E^{\text {red }}=\left(E_{p c}^{\text {red }}+E_{p a}^{r e d}\right) / 2\right)$. 

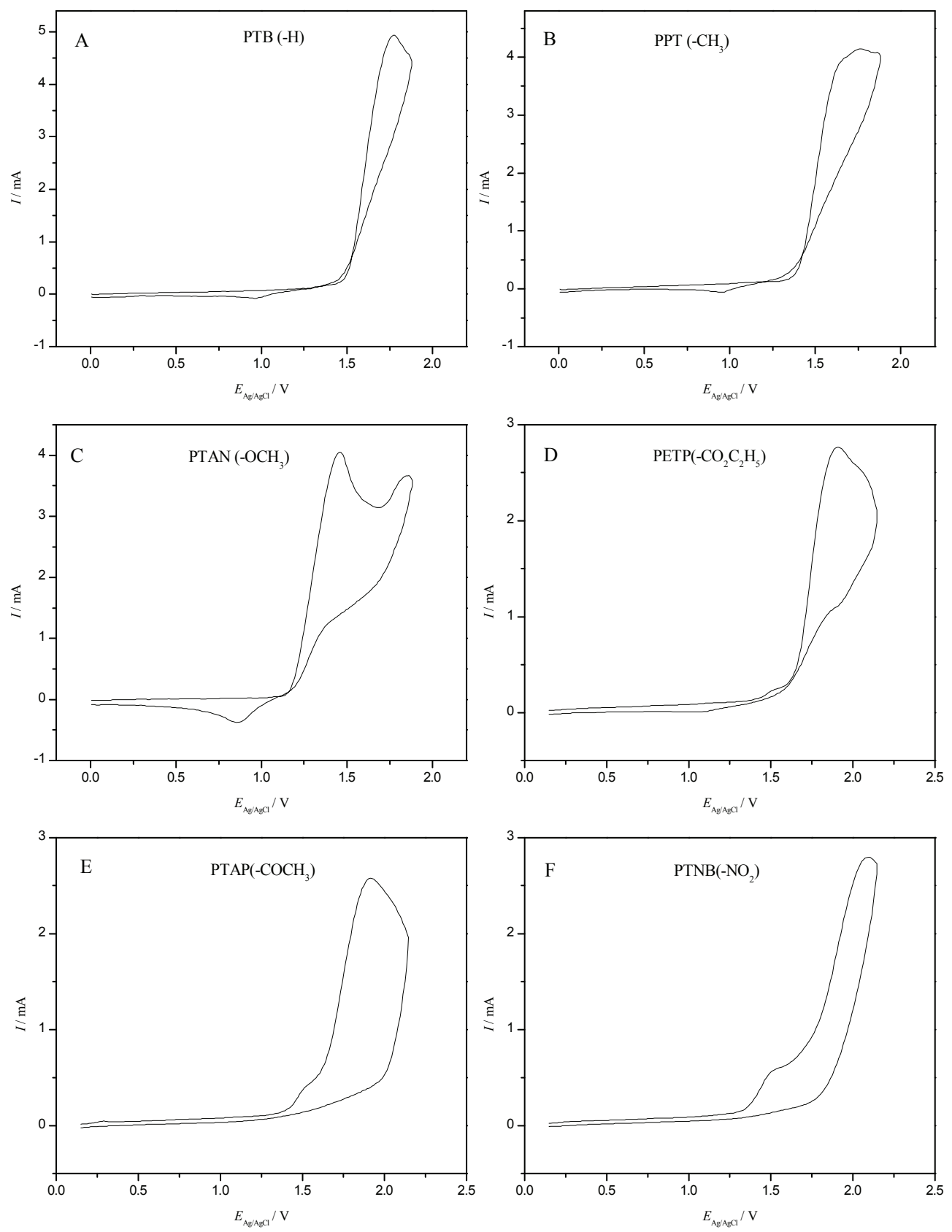

Figure 2. Cyclic voltammograms of monomers (first cycle) recorded in acetonitrile containing $0.2 \mathrm{M} \mathrm{Et}_{4} \mathrm{NBF}_{4}$ and $0.05 \mathrm{M}$ monomers: A) PTB, B) PPT, C) PTAN, D) PETB, E) PTAP and F) PTNB, at a scan rate of $\mathrm{d} E / \mathrm{d} t=100 \mathrm{mV} / \mathrm{s}$. See Table I for the acronyms of polymers. 

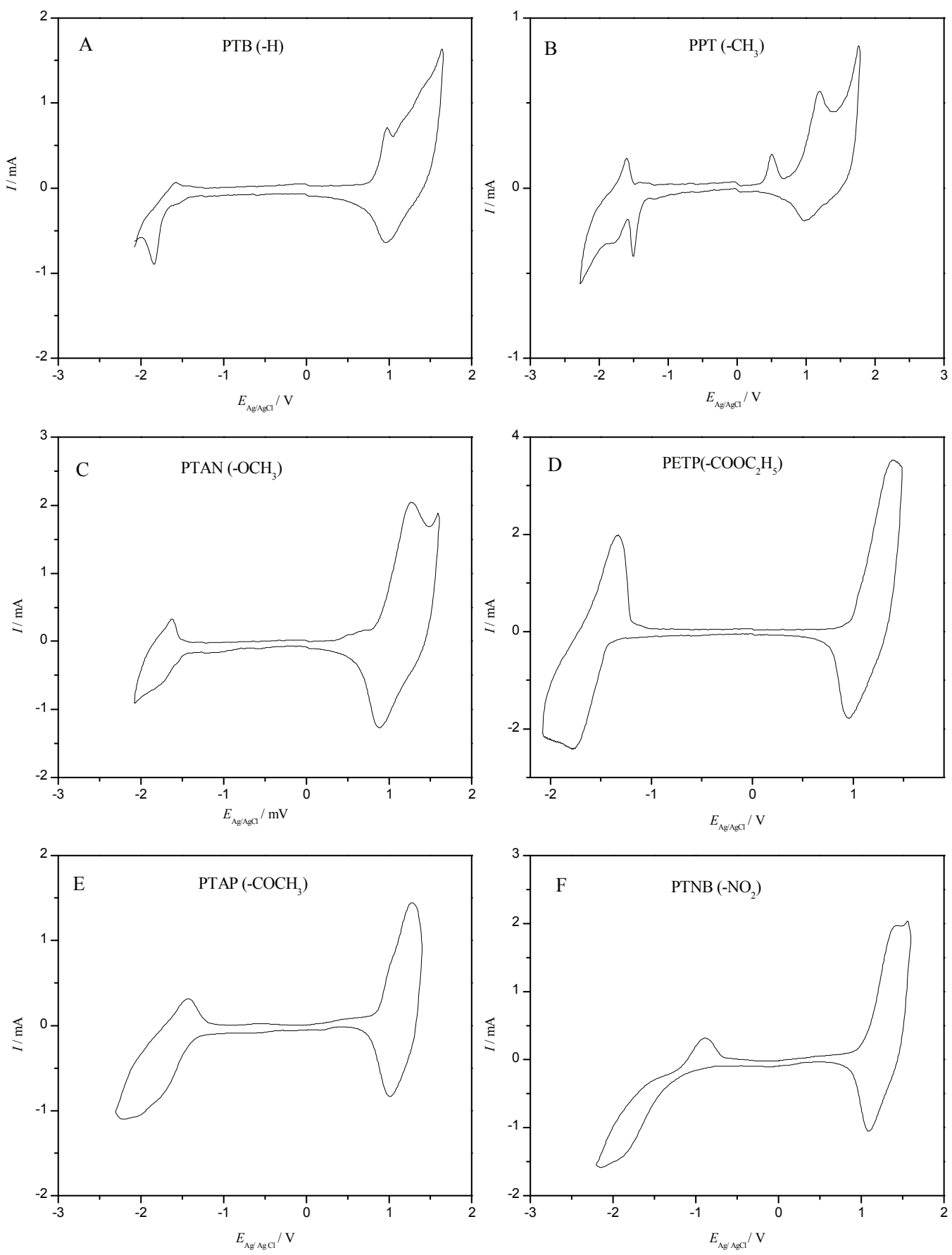

Figure 3. Cyclic voltammograms of polymer films coated on Pt electrode immersed in $0.2 \mathrm{M} \mathrm{Et}_{4} \mathrm{NBF}_{4}$ acetonitrile solution: A) PTB, B) PPT, C) PTAN, D) PETB, E) PTAP, F) PTNB, at a scan rate of $100 \mathrm{mV} / \mathrm{s}$. See Table I for acronyms.

Changes in the molecular structure of a monomer affect the voltammetric response of the monomer and the polymer film in various ways. The effect of substitution on the redox properties of the monomers and polymers stem from the interplay of steric and electronic (resonance/inductive) factors. The latter can be estimated from Hammett $\sigma$ constants [56]. Since the substituents on the phenyl group in the monomers we tested are in the para position, correlations with $\sigma_{\mathrm{p}}$ constants were deemed most appropriate, where $\sigma_{\mathrm{p}}$ 
is the sum of the inductive and resonance contributions $\left(\sigma_{\mathrm{i}}+\sigma_{\mathrm{r}}\right)$. It is important to note that these effects do not always work in the same direction. $(57,58-62)$. Table II lists the $\sigma_{\mathrm{i}}, \sigma_{\mathrm{r}}$, and $\sigma_{\mathrm{p}}$ constants, the ionization potential for the monomers, the oxidation potentials of the monomers, the formal redox potentials for their respective polymers and the heat of formation for the monomers. Figures 4,5 and 6 show the respective correlations with $\sigma_{p}$ for the monomers and polymers These trends are as expected with the potentials shifting cathodically (more negative direction) for electron donating substituents $\left(\sigma_{\mathrm{p}}<0\right)$ and anodically (more positive potentials) for electron withdrawing groups $\left(\sigma_{\mathrm{p}}>0\right)$. These new results are in agreement with published results $(15,56,58-62)$.

Table II. $\sigma_{\mathrm{i}}, \sigma_{\mathrm{r}}, \sigma_{\mathrm{p}}$, oxidation potential, ionization potential and formal potentials of $\mathrm{p}$-and $\mathrm{n}$-doping and heat of formation of the monomers in gas phase as well as in acetonitrile.

\begin{tabular}{|c|c|c|c|c|c|c|c|c|c|c|}
\hline \multirow{2}{*}{ Monomers } & \multirow{2}{*}{$\begin{array}{c}\text { Acronym for } \\
\text { Polymer }\end{array}$} & \multicolumn{3}{|c|}{ Hammett values $^{56}$} & \multirow{2}{*}{$\begin{array}{c}E_{\mathrm{ox}, \mathrm{Ag} / \mathrm{AgCl}} \\
/ \mathrm{V}\end{array}$} & \multirow{2}{*}{$\begin{array}{c}\text { Ionization } \\
\text { potentials } \\
\text { /eV }\end{array}$} & \multirow{2}{*}{$\begin{array}{c}\Delta H_{f} / \\
\mathrm{kcal} / \mathrm{mol} \\
\text { in gas phase }\end{array}$} & \multirow{2}{*}{$\begin{array}{c}\Delta H_{f} / \\
\mathrm{kcal} / \mathrm{mol} \\
\text { in } \mathrm{CH}_{3} \mathrm{CN}\end{array}$} & \multicolumn{2}{|c|}{ Polymer } \\
\hline & & $\sigma_{\mathrm{i}}$ & $\sigma_{\mathrm{r}}$ & $\sigma_{\mathrm{p}}$ & & & & & $\begin{array}{c}E_{\text {n-doping }} \\
/ \mathrm{V}\end{array}$ & $\begin{array}{c}E_{\mathrm{p} \text {-doping }} \\
/ \mathrm{V}\end{array}$ \\
\hline$-\mathrm{H}$ & PTB & 0 & 0 & 0 & 1.771 & 8.636 & 185.94 & 140.17 & -1.716 & 1.215 \\
\hline$-\mathrm{CH}_{3}$ & $\begin{array}{l}\text { PPT } \\
\end{array}$ & -0.05 & -0.13 & -0.18 & 1.762 & 8.394 & 182.88 & 139.09 & -1.823 & 1.150 \\
\hline$-\mathrm{OCH}_{3}$ & PTAN & 0.27 & -0.42 & -0.15 & 1.476 & 8.201 & 178.57 & 140.22 & -1.857 & 1.134 \\
\hline$-\mathrm{CO}_{2} \mathrm{C}_{2} \mathrm{H}_{5}$ & PETB & 0.20 & 0.16 & 0.36 & 1.908 & 8.930 & 184.96 & 148.70 & -1.702 & 1.156 \\
\hline$-\mathrm{COCH}_{3}$ & PTAP & 0.20 & 0.16 & 0.36 & 1.916 & 8.905 & 190.93 & 143.13 & -1.686 & 1.180 \\
\hline$-\mathrm{NO}_{2}$ & PTNB & 0.65 & 0.15 & 0.80 & 2.102 & 9.340 & 200.59 & 144.60 & -1.519 & 1.298 \\
\hline
\end{tabular}

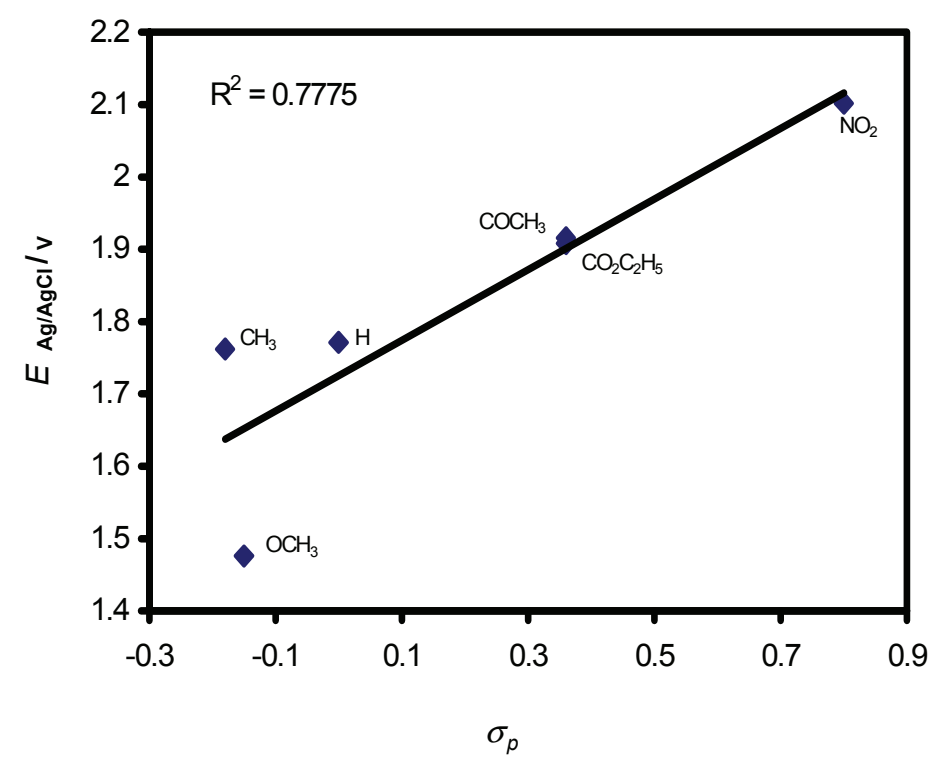

Figure 4. Plot of the oxidation potential of the monomers against $\sigma_{\mathrm{p}}$ values 


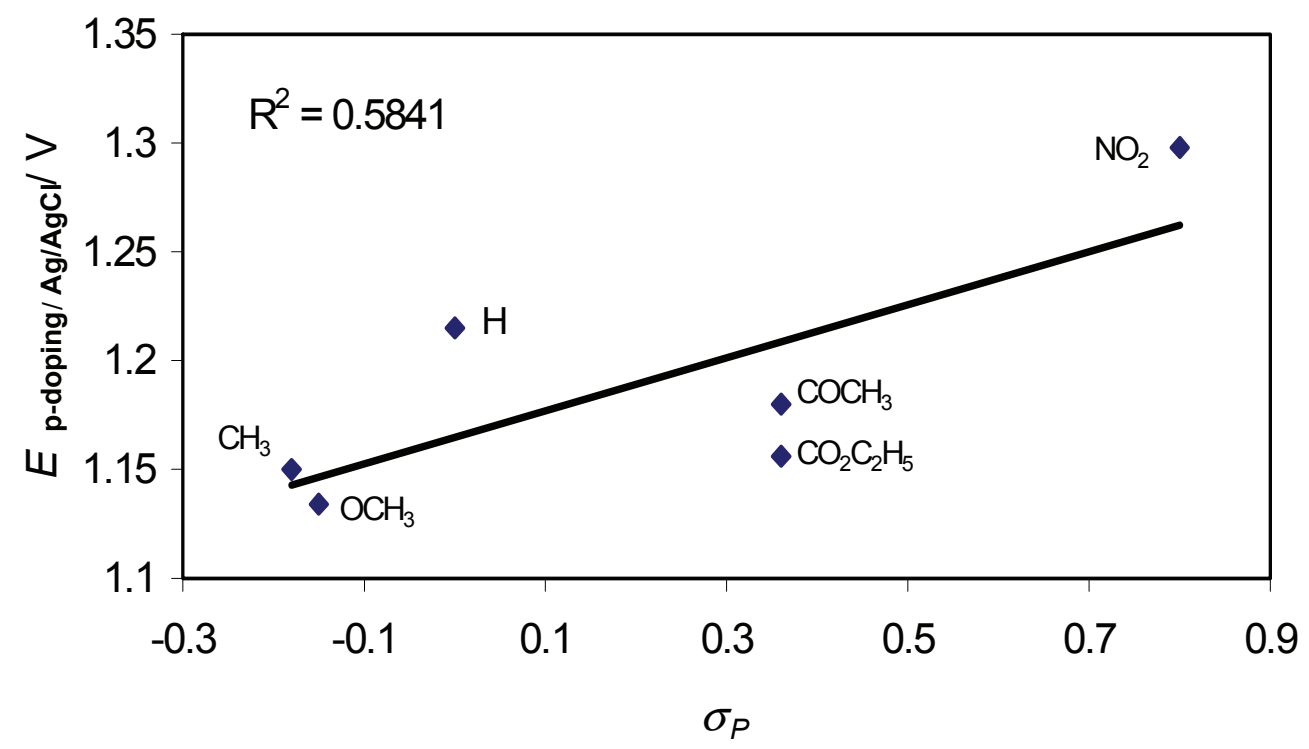

Figure 5. Plot of oxidation potential of the polymers ( $p$-doping) against $\sigma_{\mathrm{p}}$ values

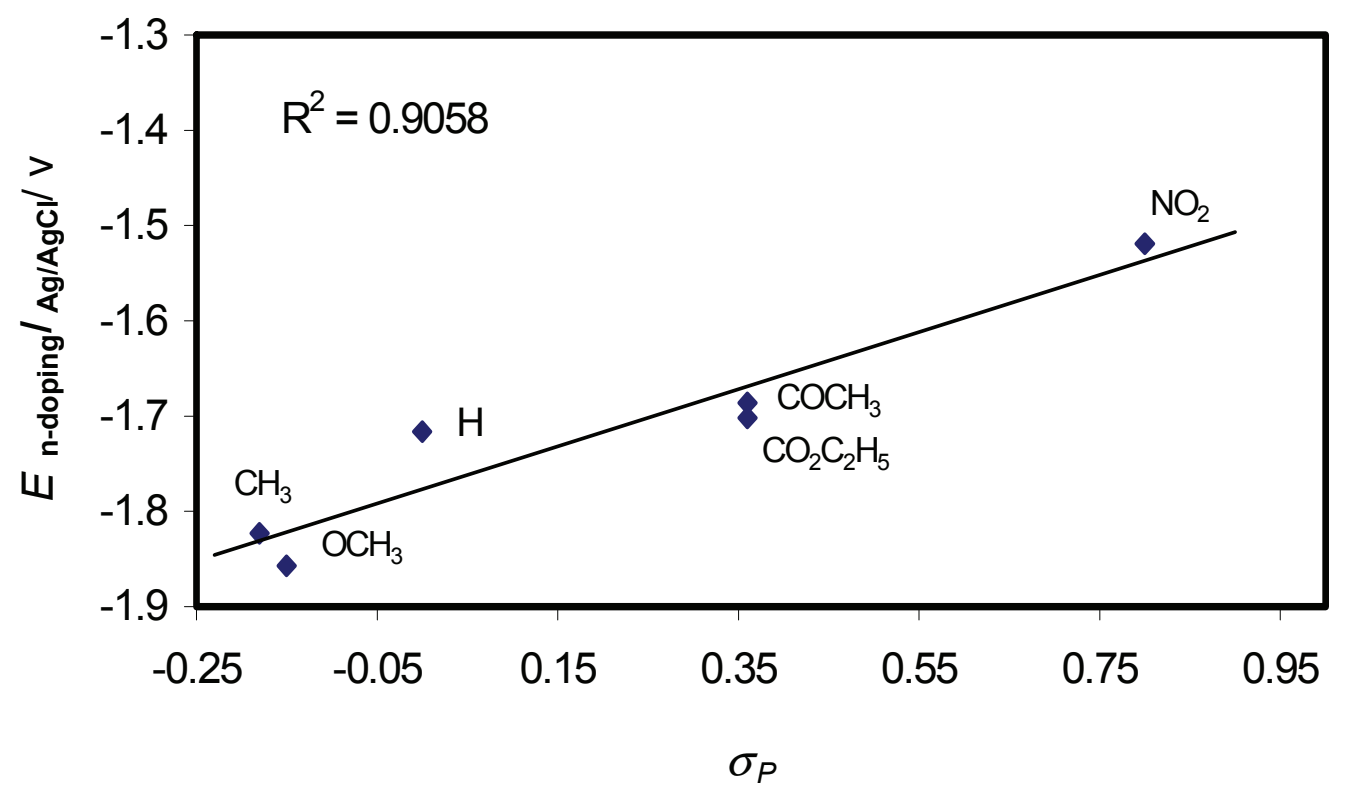

Figure 6. Plot of reduction potential of the polymers ( $n$-doping) against $\sigma_{\mathrm{p}}$ values

In Figs. 7 and 8 inductive as well as resonance effects are correlated with oxidation potentials. From these figures it is obvious that the resonance effect dominates the inductive effect $[56,63]$. Thus, the resonance effect plays a more important role to obtain good correlations between oxidation potentials of the monomers and Hammett constants (c.f. Fig. 4).

Zuman [64] pioneered a classical method for determining how the oxidation (or reduction) potential of an organic substance is affected by electron-withdrawing or electron-donating groups by studying the correlation between the oxidation and reduction potentials and Hammett constants. This procedure has a number of limitations: (a) compounds containing certain substituents, such as amino or carbonyl group, which are capable of interaction with the electroactive group via resonance, fall far from the correlation line, (b) the method is limited to substituted aromatics; it cannot be used to estimate the 
reduction (or oxidation) potentials of any other type of compounds such as conjugated polyenes, heterocyclic substances and polycyclic benzenoid and non-benzenoid aromatic hydrocarbons (PAH). Thus, we used a semiempirical method to calculate the heat of formation for the monomers in gas phase as well as in liquid phase (acetonitrile) (1a-f) (see Table I). Figures 9 and 10 show the correlation between the oxidation potentials and the heat of formation of these monomers in gas and liquid phases, respectively. It has been observed that with included solvent effect the correlation shows a smaller value of $\mathrm{R}^{2}$, which means that the correlation between the oxidation potentials and heat of formation is not as good as in the gas phase.

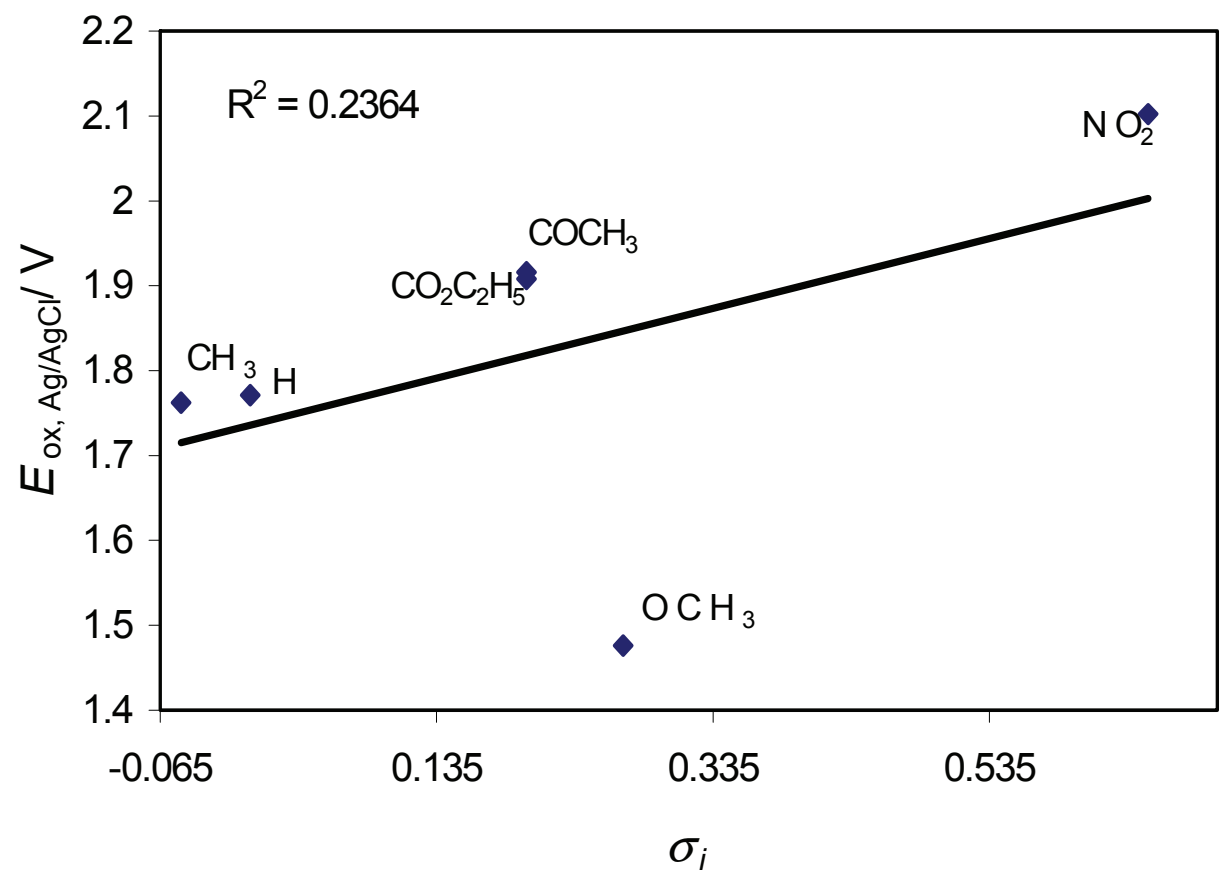

Figure 7. Plot of the oxidation potential of the monomers against $\sigma_{i}$ values

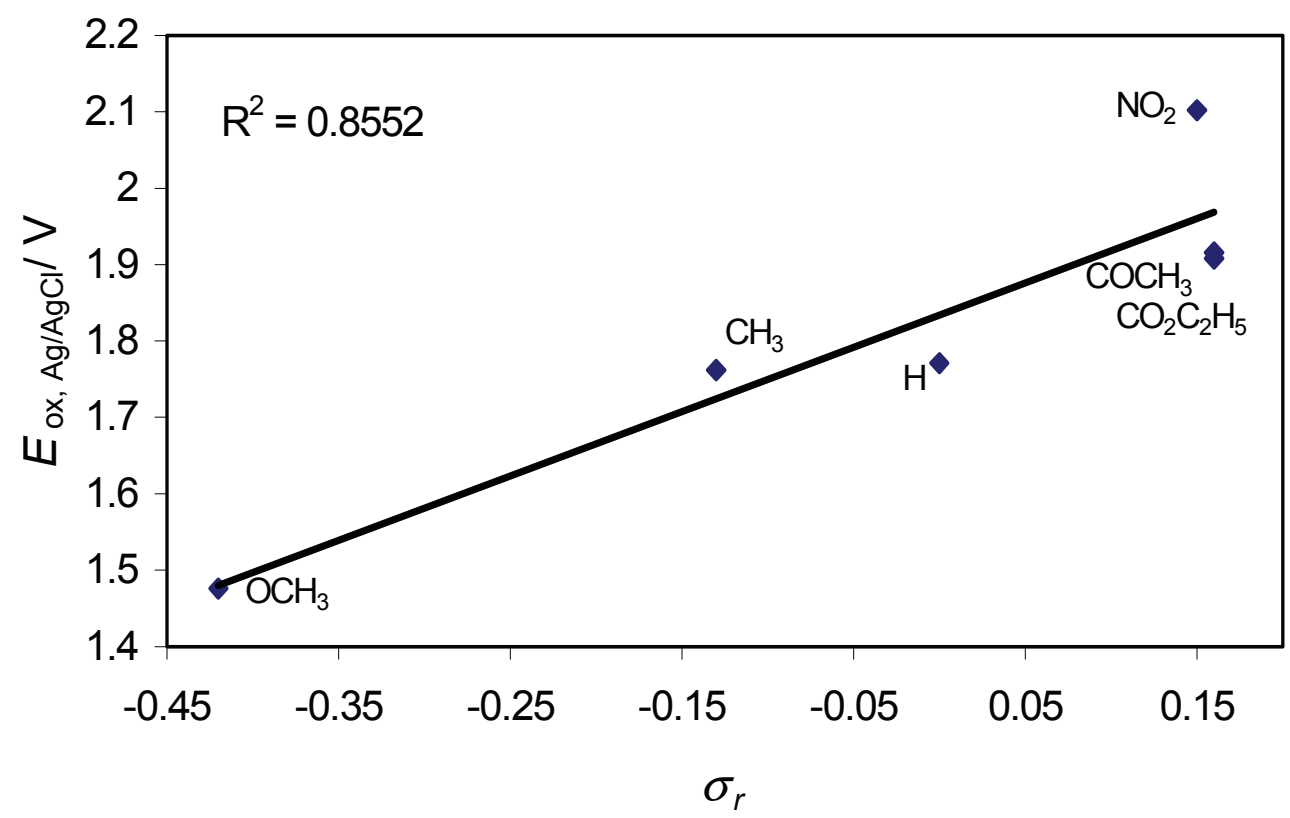

Figure 8. Plot of the oxidation potentials of the monomers against $\sigma_{\mathrm{r}}$ values 


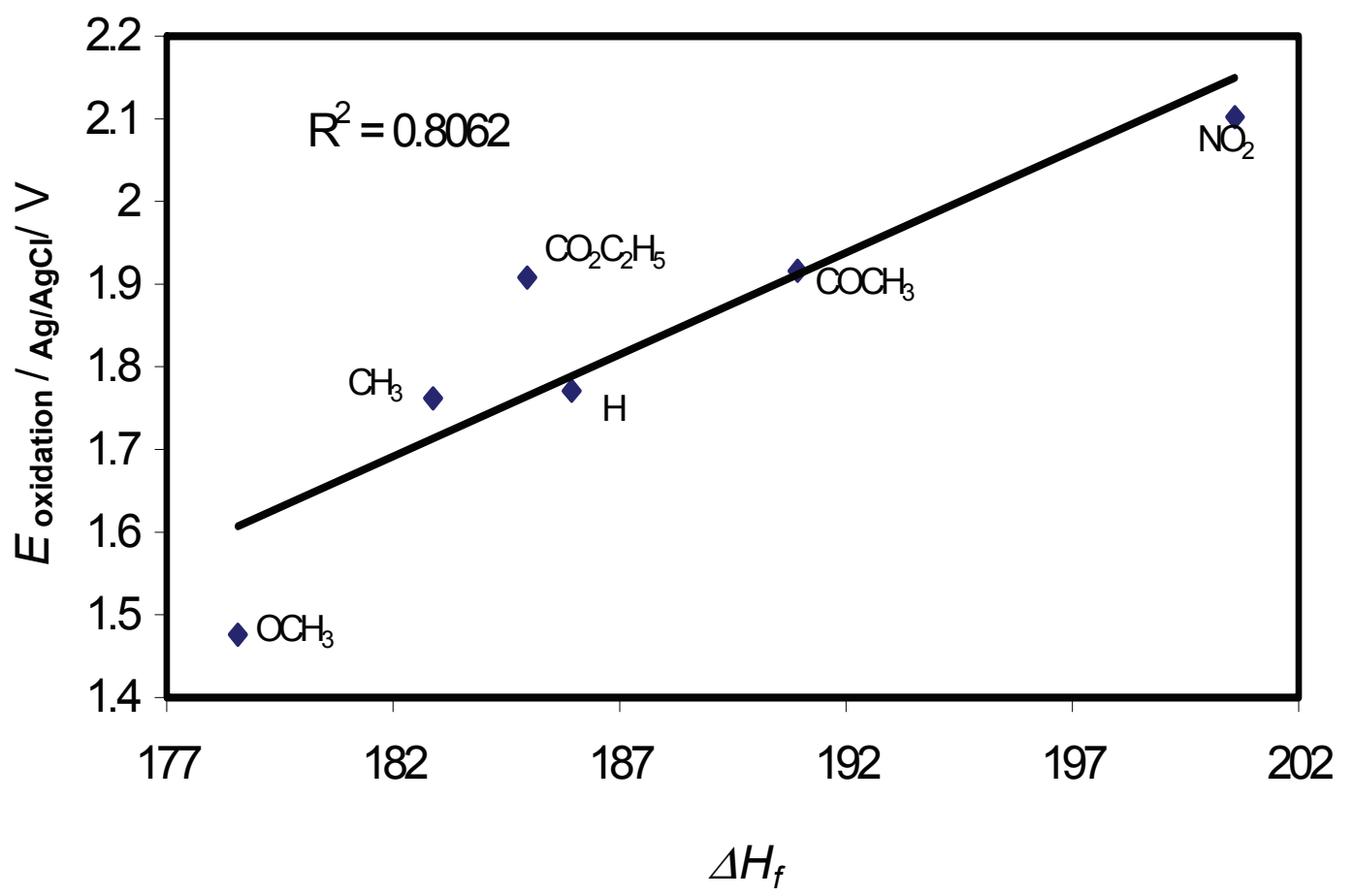

Figure 9. Plot of oxidation potentials of the monomers against heat of formation in the gas phase.

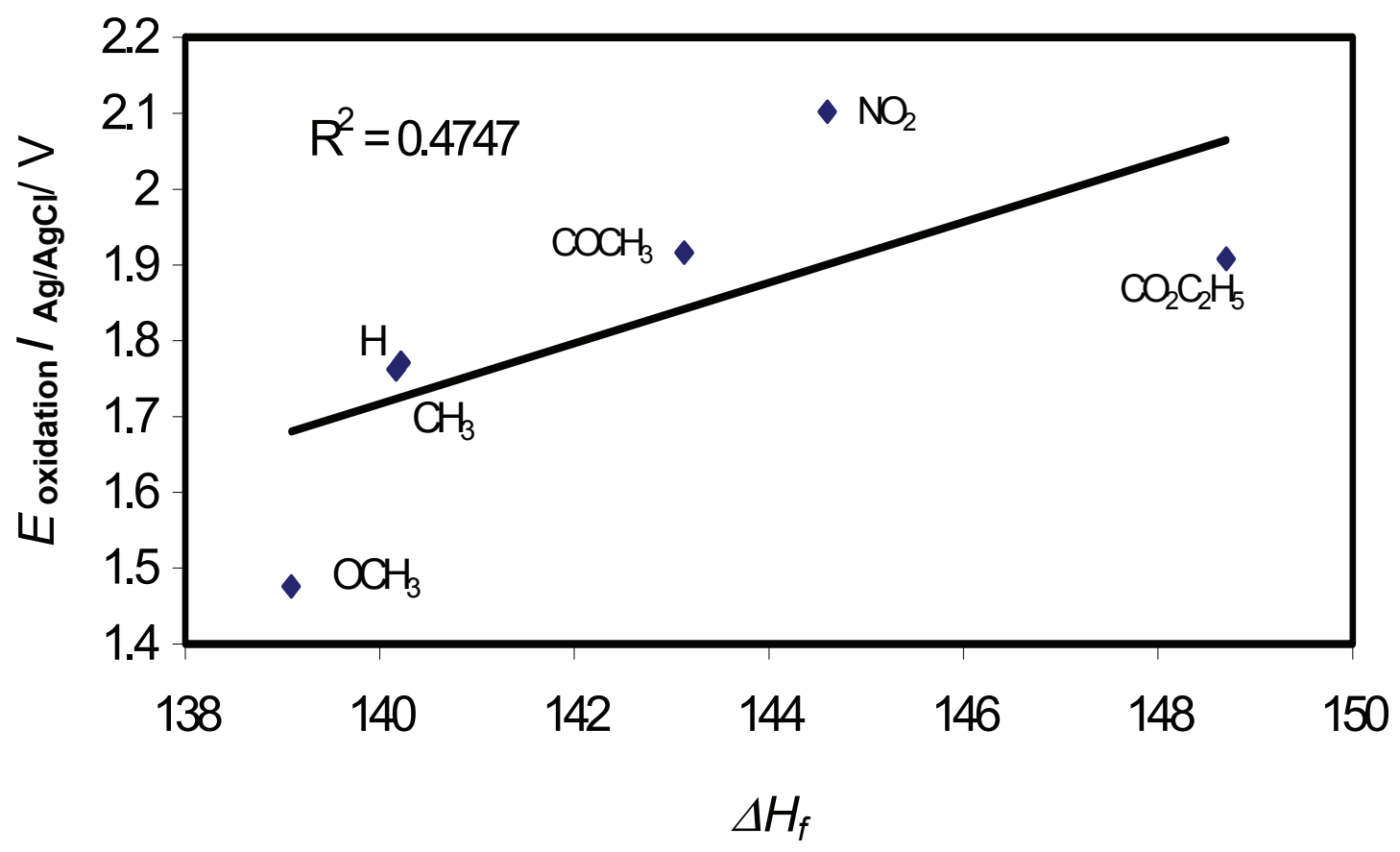

Figure 10. Plot of oxidation potentials of the monomers against heat of formation in acetonitrile.

Although $\Delta G_{f}$ is more directly related to the oxidation potential of the electrode than $\Delta H_{f}$, the correlation of the oxidation potentials of the monomers (1a-f) was based on $\Delta H_{f}$ values only. Calculation of $\Delta S_{f}$ and subsequently of $\Delta G_{f}$ is basically possible. The obtained values of both entities show considerable uncertainty. Ab initio molecular orbital (MO) methods provide total energies as the sum of electronic and nuclear-nuclear repulsion energies for molecules; isolated in vacuum, without vibration at $0 \mathrm{~K}$. From the $0 \mathrm{~K}$ potential surface and using the harmonic oscillator approximation, they can calculate the 
vibrational frequencies, $v_{i}$, of the normal modes of vibration. Using these, they can calculate vibrational, rotational and translational contributions to the thermodynamic quantities that arise from heating the system from 0 to $T \mathrm{~K}$. However, at $298.15 \mathrm{~K}$, due to higher number of degrees of freedom the degree of uncertainty is larger and therefore this calculated values of $\Delta G_{f}$ have too large uncertainty.

As already discussed, the initial step of the electropolymerization reaction is a oneelectron oxidation of the monomer resulting in its radical cation. The probability of this step should be related to the ionization potential of the molecule, which in turn corresponds to the energy of generating a radical cation during the oxidative process (Table II). The correlation between the oxidation potentials and the ionization potentials of the monomers is indeed fairly high (Figure 11). It is actually much better than the correlation between the oxidation potentials and the heats of formation calculated semiempirically. Although the absolute range of values of the ionization potentials shows a variation similar to the variation of the heat of formation the predictive capability of the ionization potentials is obviously better.

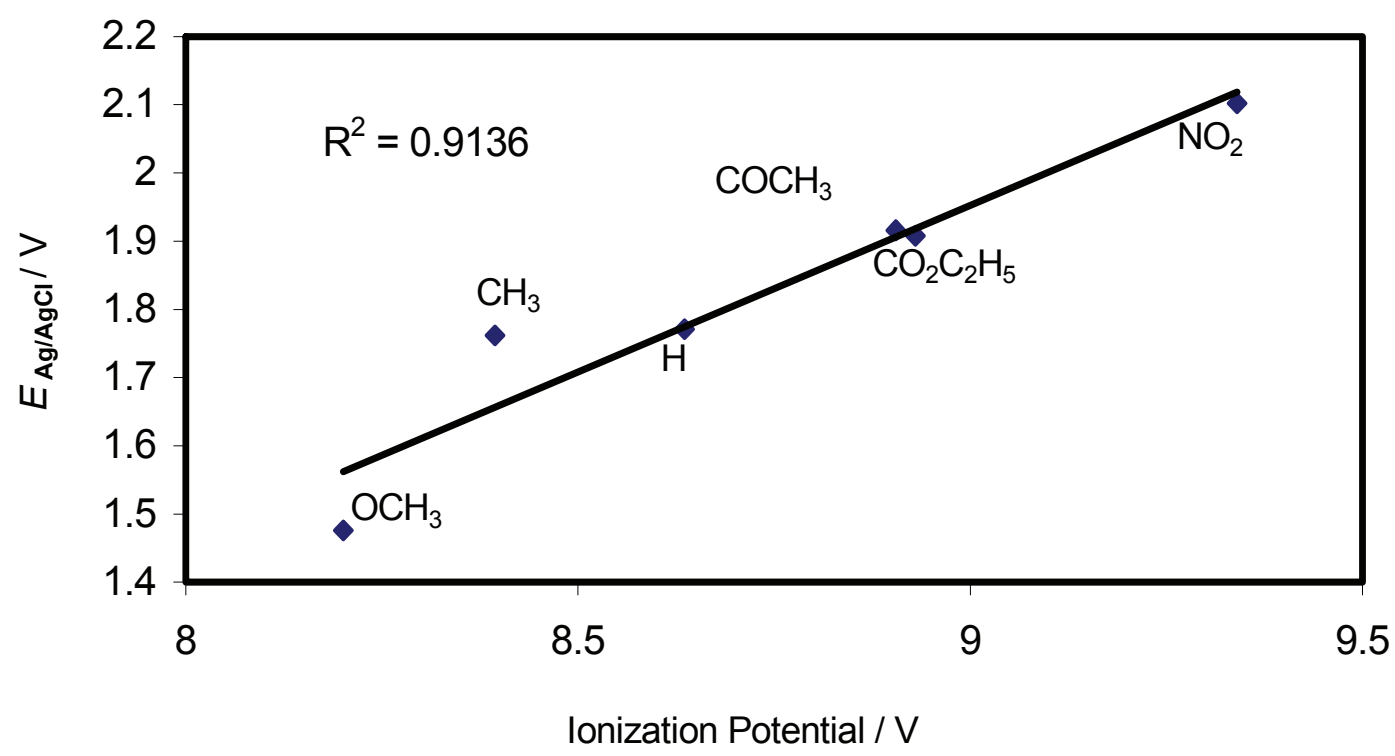

Figure 11. Plot of the oxidation potential of the monomers against the ionization potentials.

\section{References}

1. H. Shirakawa, E.J. Louis, A.G. MacDiramid, C.K. Chiang and A.H. Heeger. J.Chem.Soc., Chem. Commun., 578 (1977).

2. R.D. McCullough. Adv. Mater., 10, 93 (1998).

3. H. Sirringhaus, P.J. Brown, R. H. Friend, M.M. Nielesn, K. Bechgaard, B. M.W. Langeveld-Voss, A.J. Spiering, R.A.J. Janseen, E. W. Meijer, P. Herwig and D. M. De Leeuw. Nature., 401, 685 (1999).

4. R.D. McCullough, R.D. Lowe, M. Jayaraman and D. L. Anderson. J.Org. Chem., 58, 904 (1993).

5. M.R. Andersson, M. Berggren, O. Inganäs, G. Gustafsson, J.C. GustafssonCarlberg, D. Hjertberg and O. Wennerström, Macromolecules., 28, 7525 (1995).

6. M. Berggren, O. Inganäs, T. Granlund, S. Guo, G. Gustafsson and M.R. Andersson. Synth.Met., 76, 121 (1996). 
7. L. Roman, W. Mammo, L. Petterson, M. Andersson and O. Inganäs. Adv. Mat., 10, 774 (1998).

8. T. Granlund, M. Theander, M. Berggren, M. Andersson, A, Ruseckas, V. Sundström, G. Björk, M, Granström and O. Inganäs. Chem. Phys. Lett., 288, 879 (1998).

9. J.L. Bredas, R. Silbey, D.S. Boudreaux, and R.R. Chance, J. Am. Chem. Soc., 105, 6555 (1983).

10. C. Arbizzani, M. Catellani, M. Mastragostino, and C. Mingazzini. Electrochim. Act., 40, 1871 (1995).

11. D.M.D. Leeuw, M.M.J. Simenon, A.R. Brown,and R.E.F. Einerhand. Synth. Met., 87, 53 (1997).

12. M. Sato, S.Tanaka and K. Kaeriyama. J Chem Soc, Chem Commun., 1725 (1987).

13. M. Sato, S. Tanaka and K Kaeriyama. Makromol Chem., 190, 1233 (1989).

14. M. Onoda, H. Nakayama, S. Morita and K, Yashino. Synth Met., 55-57, 275 (1993).

15. D. J. Guerrero, X. Ren, J. P. Ferraris. Chem Mater., 6, 1437 (1994).

16. T.-A. Chen and R.D. Rieke. J. Am. Chem. Soc., 114, 10087 (1992).

17. R.D. McCullough and R.D. Lowe. J. Chem. Soc. Chem. Commun., 70 (1992).

18. M.R. Andersson, D. Salse, M. Berggren, H. Järvinen, T. Hjertberg, O. Inganäs, O. Wennerstöm and J.-E Österholm, Macromolecules., 27, 6503 (1994).

19. S. Ando and M. Ueda. Synth. Met., 129, 207 (2002).

20. G. Gritzner and J. Kuta. Pure Appl.Chem., 56, 461 (1984).

21. P. Hohenberg and W. Kohn. Phys. Rev., 136, B864 (1964).

22. W. Kohn and L. J. Sham. Phys. Rev., 140, A1133 (1965).

23. D. R. Salahub and M. C. Zerner. The Challenge of $d$ and f Electrons: theory and computation, Ed., ACS, Washington, D.C (1989).

24. R. Ditchfield, W. J. Hehre and J. A. Pople. J. Chem. Phys., 54, 724 (1971).

25. W. J. Hehre, R. Ditchfield and J. A. Pople. J. Chem. Phys., 56, 2257 (1972).

26. P. C. Hariharan and J. A. Pople. Mol. Phys., 27, 209 (1974).

27. M. S. Gordon. Chem. Phys. Lett., 76, 163 (1980).

28. P. C. Hariharan and J. A. Pople. Theo. Chim. Acta., 28, 213 (1973).

29. J.-P. Blaudeau, M. P. McGrath, L. A. Curtiss and L. Radom. J. Chem. Phys., 107, 5016 (1997).

30. M. M. Francl, W. J. Pietro, W. J. Hehre, J. S. Binkley, D. J. DeFrees, J. A. Pople and M. S. Gordon. J. Chem. Phys., 77, 3654 (1982).

31. R. C. Binning Jr. and L. A. Curtiss. J. Comp. Chem., 11, 1206 (1990).

32. V. A. Rassolov, J. A. Pople, M. A. Ratner and T. L. Windus. J. Chem. Phys., 109, 1223 (1998).

33. V. A. Rassolov, M. A. Ratner, J. A. Pople, P. C. Redfern and L. A. Curtiss. J. Comp. Chem., 22, 976 (2001).

34. G. A. Petersson and M. A. Al-Laham. J. Chem. Phys., 94, 6081 (1991).

35. G. A. Petersson, A. Bennett, T. G. Tensfeldt, M. A. Al-Laham, W. A. Shirley and J. Mantzaris. J. Chem. Phys., 89, 2193 (1988).

36. J. S. Binkley, J. A. Pople and W. J. Hehre. J. Amer. Chem. Soc., 102, 939 (1980).

37. M. S. Gordon, J. S. Binkley, J. A. Pople, W. J. Pietro and W. J. Hehre. J. Amer. Chem. Soc., 104, 2797 (1982).

38. W. J. Pietro, M. M. Francl, W. J. Hehre, D. J. Defrees, J. A. Pople and J. S. Binkley. J. Amer. Chem. Soc., 104, 5039 (1982).

39. K. D. Dobbs and W.J. Hehre. J. Comp. Chem., 7, 359 (1986). 
40. K. D. Dobbs and W.J. Hehre. J. Comp. Chem., 8, 861 (1987).

41. K. D. Dobbs and W.J. Hehre. J. Comp. Chem., 8, 880 (1987).

42. T. Clark, J. Chandrasekhar, G. W. Spitznagel and P. v. R. Schleyer. J. Comp. Chem., 4, 294 (1983).

43. M. Pelletier and F. Brisse. Acta Crystallogr., Section C. Cryst. Struct. Commun., 50, 1942 (1994).

44. E. F. Paulus, R. Dammel, G. Kampf, P. Wegener, K. Siam, K. Wolinski and L. Schafer. Acta Crystallogr., Section B, Struct. Sci., 44, 509 (1988).

45. G. Barbarella, M. Zambianchi, A. Bongini and L. Antolini. Adv. Mater. 4, 282 (1992).

46. M. Dewar and W. Thiel. J. Am. Chem. Soc., 99, 4499 (1977).

47. Gaussian 98, Revision A.3, M. J. Frisch, G. W. Trucks, H. B. Schlegel, G. E. Scuseria, M. Robb, J. R.Cheeseman, V. G. Zakrzewski, J. A. Montgomery, Jr., R. E. Stratmann, J. C. Burant, S. Dapprich, J. M. Millam, A. D. Daniels, K. N. Kudin, M. C. Strain, O. Farkas, J. Tomasi, V. Barone, M. Cossi, R. Cammi, B. Mennucci, C. Pomelli, C. Adamo, S. Clifford, J. Ochterski, G. A. Petersson, P. Y. Ayala, Q. Cui, K. Morokuma, D. K. Malick, A. D. Rabuck, K. Raghavachari, J. B. Foresman, J. Cioslowski, J. V. Ortiz, B. B. Stefanov, G. Liu, A. Liashenko, P. Piskorz, I. Komaromi, R. Gomperts, R. L. Martin, D. J. Fox, T. Keith, M. A. Al-Laham, C. Y. Peng, A. Nanayakkara, C. Gonzalez, M. Challacombe, P. M. W. Gill, B. Johnson, W. Chen, M. W. Wong, J. L. Andres, C. Gonzalez, M. Head-Gordon, E. S. Replogle and J. A. Pople, Gaussian, Inc., Pittsburgh, (1998).

48. J. Roncali. Chem. Rev., 92, 711 (1992).

49. J.F. Ambrose and R.F. Nelson. J. Electrochem. Soc., 92, 1161 (1968).

50. R.N. Adams. Acc. Chem. Res., 2, 175 (1969).

51. M.A. D Oliveira, H.F. Dos Santos and W.B De Almeida. Phys. Chem. Chem. Phys., 2, 3373 (2000).

52. O. Haba, T. Hayakawa, M. Ueda, H. Kawaguchi and T. Kawazoe. React. Func. Polym., 37, 163 (1998).

53. T. Hayakawa, K. Fukukawa, M. Morishima, K. Takeuchi, M. Asai, S. Ando and M. Ueda. J. Poly. Sci. Part A, Polym. Chem., 39, 2287 (2001).

54. M. Frechette, M. Belletete, J.-Y. Bergeron, G. Durocher and M. Leclerc, Synth. Met., 84, 223 (1997).

55. G. Dian, G. Barbey and B. Decroix. Synth. Met., 13, 281 (1986).

56. J. March. Advanced Organic Chemistry, PP 280ff; John Wiley \& Sons: New York, (1992).

57. A. Rudge, J. Davey, I. Raistrick, S. Gottesfeld and J.P. Ferraris, Electrochimica Acta., 39, 273 (1994).

58. Y. Gofer, J.G. Killian, H. Sarker, T.O. Pochler and P.C. Searson. J. Electroanal. Chem., 413, 103 (1998).

59. R.J. Wahman, J. Bargon and A.F. Diaz. J. Phys. Chem., 87, 1459 (1983).

60. R.J. Wahman, A.F. Diaz and J. Bargon. J. Phys. Chem., 88, 4343 (1984).

61. H. Sarker, Y. Gofer, J.G. Killian, T.O. Pohler and P.C. Searson, Synth. Met., 88, 179 (1997).

62. E. Kinbara, Y. Kunugi, Y. Harima and K. Yamashita. Synth. Met., 114, 295 (2000).

63. F.A. Carey and R.J. Sundberg, Advanced Organic Chemistry, p 196-210, Plenum Publishing Corporation: New York, (1993). 
64. Zuman, P. Substituent Effects in Organic Polarography, Plenum: New York, (1967). 